\title{
Real-time Data Visualisation using Mobile Apps to Assess Students' Learning in a Large Group Teaching
}

\author{
Thwin, E. P. A.
}

\section{Introduction}

Although an increasing number of health professional students are using smartphones and other mobile devices for their learning, Ellaway (2014) argues that mobile learning in medical education is generally informal and implicit. For the most part, educators instruct students to turn off their mobile phones during lectures or to set them to silent mode.

However, I have used mobile apps such as Kahoot, Socrative, Mentimeter, and Padlet as web-based audience response systems to assess health professional students' understanding during anatomy lessons. I have asked students to use their mobile phones for in-class question-and-answer sessions and have found that mobile apps with real-time data capturing and visualisation may be promising platforms for tracking students' progress and providing them with formative feedback. Based on my experience using mobile apps, I prepared the following tips for health professional educators for the effective and efficient use of such apps in large group teaching.

\section{Inform and instruct students}

Students must be informed of the educational purpose of using mobile apps in the classroom. Otherwise, because they are usually instructed not to use their phones during class, they may be confused.

\section{Sign up for free app accounts}

Most apps allow users to sign up for a free account, and they usually offer educators the opportunity to use a free basic plan.

\section{Dr. Eugenie Phyu Aye Thwin,}

Senior Lecturer, Department of Medical Sciences and Paramedicine, School of Health and Social Sciences, Nanyang Polytechnic, Singapore

Email: eugenie phyu ave thwin@nyp.edu.sg
Some schools subscribe to an institutional license for certain apps; if so, such apps are often the best option for educators. Apps should also be free for students to use; thus, it is advisable to check the terms and conditions of the selected apps before using them with students.

\section{Select the objective type of questions}

Single-response multiple choice questions or true/false questions are best when educators want to quickly check students' understanding of a lesson. The questions can be created adhoc, but it is advisable to prepare them ahead of time. Students should take approximately one to two minutes to answer the questions, and the teacher should interpret students' responses within 30 seconds (Wiliam, 2011b).

\section{Ensure legibility of questions}

As students will use their mobile phones to answer the questions, the text and any accompanying images should be legible on their mobile phone screens. Therefore, it is recommended that educators check the readability of the questions on their own phones before using the questions in the classroom.

\section{Test run apps before actual implementation}

It is advisable to complete a test run of the selected app with a colleague or a volunteer student to ensure sure that everything functions properly. Any technical issues should be identified and rectified before using the app in class.

\section{Set netiquette rules when using open- ended questions}

It is essential to set the netiquette rules when working with open-ended questions. These rules should include avoiding offensive language and slang, not making negative comments about the posts of others, and 
respecting other students' opinions (MintuWinmsatt et al., 2010). Students should be briefed beforehand on these rules to help avoid conflicts and unprofessional behaviours.

\section{Maintain the anonymity of students' responses}

To contribute to a safe learning environment during formative assessment, I recommend capturing students' answers anonymously. Furthermore, Robertson (2000) found that when students believe that their responses are anonymous, their active participation is enhanced. It is therefore advisable to disable personal identifiers when setting up the apps.

\section{Provide formative feedback to students}

I recommend posting the questions midway through a lesson and providing students with formative feedback based on their responses (Wiliam, 2011b). Furthermore, educators can use the responses to decide whether the lesson requires additional explanation or whether the class is ready to move on.

\section{Review available reports on students' responses}

Some apps allow educators to download saveable reports on students' responses. Such features are even available in the free plans of some apps. Educators should modify their teaching approaches by identifying the levels of students' understanding and their learning needs (Wiliam, 2011a). Reporting features can assist educators in making such identifications.

\section{Conclusion}

The article presents tips for using apps as tools in assessing students' progress during a lecture. Tips are focused on the most important and useful elements of the apps based on my own experiences and evidence from the literature. Thus, this article may be of assistance to educators who are eager to use technology to assess their students' understanding of a lesson and determine the pacing and direction of a lecture.

\section{Statement of Conflicting Interest}

The author has no conflicts of interest to declare.

\section{References}

Ellaway, R. (2014). The informal and hidden curricula of mobile device use in medical education. Medical Teacher, 36, 1. pp. 8991.

Mintu-Winmsatt, A., Kernek, C. \& Lozada, H. R. (2010). Netiquette: Make it part of your syllabus. Journal of Online Learning and Teaching, 6, 1. pp. 264-267.

Robertson, L. J. (2000). Twelve tips for using a computerised interactive audience response system. Medical Teacher, 22, 3. pp. 237-239.

Wiliam, D. (2011a). The case for formative assessment. Embedded formative assessment. Solution Tree Press.

Wiliam, D. (2011b). Eliciting evidence of learners' achievement. Embedded formative assessment. Solution Tree Press. 